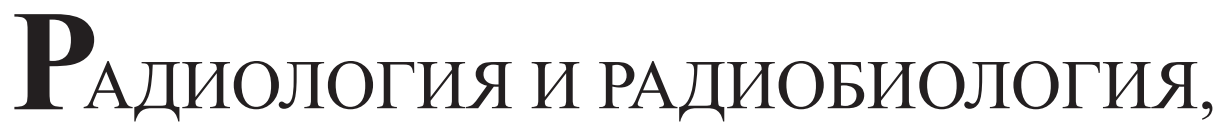 РАДИАЦИОННАЯ БЕЗОПАСНОСТЬ
}

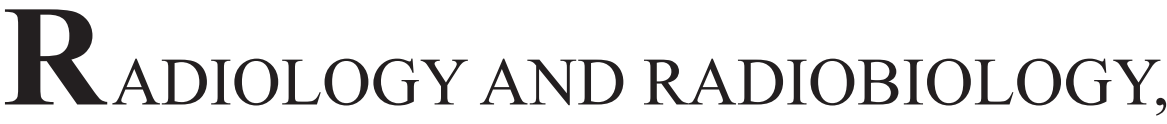 RADIATION SAFETY}

УДК 614.876(476)

\section{ПАРАМЕТРЫ СМЫВА РААИОНУКАИАОВ \\ С ВОАОСБОРА Р. ВИЛИЯ В НАЧААЬНЫЙ ПЕРИОА ПОТЕНЦИАЛЬНОЙ АВАРИИ НА БЕЛОРУССКОЙ АЭС}

\author{
о. М. ЖУКОВА ${ }^{1)}$, В. В. КЛЯУС ${ }^{1)}$, Е. В. НИКОЛАЕНКО \\ ${ }^{1)}$ Научно-практический центр гигиены, \\ ул. Академическая, 8, 220012, г. Минск, Беларусь
}

\begin{abstract}
Представлены результаты расчетов параметров смыва радионуклидов с водосборных территорий р. Вилия и оценка содержания радионуклидов в воде при предполагаемой аварии на Белорусской АЭС. Приведены прогнозные оценки доз облучения населения, проживающего вблизи Белорусской АЭС, от потребления питьевой воды, загрязненной радионуклидами ${ }^{137} \mathrm{Cs},{ }^{90} \mathrm{Sr}$ и ${ }^{131} \mathrm{I}$ в результате возможной запроектной аварии.
\end{abstract}

Ключевые слова: радионуклид; вода; Белорусская АЭС; запроектная авария; р. Вилия; модуль смыва; коэффициент смыва; эффективная доза.

\section{Образец цитирования:}

Жукова ОМ, Кляус ВВ, Николаенко ЕВ. Параметры смыва радионуклидов с водосбора р. Вилия в начальный период потенциальной аварии на Белорусской АЭС. Журнал Белорусского государственного университета. Экология. 2020;3:53-59. https://doi.org//10.46646/2521-683X/2020-3-53-59
For citation:

Zhukova OM, Kliaus VV, Nikalaenka AU. Parameters of radionuclide washout from the catchment area of the Viliya river after the accident at the Belarusian NPP. Journal of the Belarusian State University. Ecology. 2020;3:53-59. Russian.

https://doi.org//10.46646/2521-683X/2020-3-53-59

\section{Авторы :}

Ольга Митрофановна Жукова - кандидат технических наук, доцент; старший научный сотрудник лаборатории радиационной безопасности.

Виктория Вячеславовна Кляус - кандидат биологических наук; старший научный сотрудник лаборатории радиационной безопасности.

Елена Владимировна Николаенко - кандидат медицинских наук; заведующий лабораторией радиационной безопасности.

\footnotetext{
Authors:

Olga M. Zhukova, $\mathrm{PhD}$ (engineering), docent; senior researcher of the laboratory of radiation safety.

omzhukova2018@gmail.com

Victoria V. Kliaus, PhD (biology); senior researcher of the laboratory of radiation safety.

vkliaus@gmail.com

Elena V. Nikolaenko, $\mathrm{PhD}$ (medicine); head of the laboratory of radiation safety.

nikolaenko67@gmail.com
} 


\title{
PARAMETERS OF RADIONUCLIDE WASHOUT FROM THE CATCHMENT AREA OF THE VILIYA RIVER AFTER THE ACCIDENT AT THE BELARUSIAN NPP
}

\author{
O. M. ZHUKOVA, V. V. KLIAUS, A. U. NIKALAENKA ${ }^{\mathrm{a}}$ \\ ${ }^{a}$ Scientific practical centre of hygiene, \\ 8 Akademičnaja Street, Minsk 220012, Belarus \\ Corresponding author: O.M. Zhukova (omzhukova2018@gmail.com)
}

This article presents the results of calculation the parameters of radionuclides washout from the catchment areas of the Viliya river and the assessment of activity concentrations of radionuclides in water in case of beyond design basis accident at the Belarusian NPP. The results of estimates of the exposure doses to public living near the Belarusian NPP from the consumption of drinking water contaminated with ${ }^{137} \mathrm{Cs},{ }^{90} \mathrm{Sr}$ and ${ }^{131} \mathrm{I}$ radionuclides as a result of a possible beyond design basis accident are presented.

Keywords: radionuclide; water; Belarusian NPP; beyond design basis accident; Viliya; washout module; washout coefficient; effective dose.

\section{Введение}

Белорусская АЭС (далее - БелАЭС) расположена в Островецком р-не Гродненской обл. БелАЭС единственная белорусская атомная электростанция с реакторами типа ВВЭР, которая относится к объектам 1 категории по потенциальной радиационной опасности. В соответствии с международными рекомендациями и национальными нормативными документами для объектов 1 категории оценка прогнозных последствий аварий является обязательной. Река Вилия - основной источник технического водоснабжения БелАЭС, а также главный приемник технических сточных вод от станции.

После крупной ядерной аварии особую важность представляет проблема радиоактивного загрязнения водоемов, а также рек, протекающих по загрязненной территории, поскольку они, как правило, являются для населения источником питьевой воды, продуктов рыболовства и воды для орошаемого земледелия. Так, в результате аварии на Чернобыльской АЭС в 1986 г. значительные территории бассейна р. Днепр, включая водосбор ее правого притока (р. Припять), были загрязнены долгоживущими радионуклидами ${ }^{137} \mathrm{Cs}$ и ${ }^{90} \mathrm{Sr}$, периоды полураспада которых составляют около 30 лет. Аналогично при аварии на АЭС Фукусима-1 в 2011 г. произошло загрязнение ${ }^{137} \mathrm{Cs}$ бассейнов речных систем Абукумы, Мано, Нитта, Ота, Укеда, Маеда, Кума и др., которые все впадают в Тихий Океан, вынося туда радиоцезий как в растворе, так и во взвеси. Миграция радионуклидов по речным системам приводит к их выносу за пределы изначально загрязненных территорий, включая трансграничный перенос [1].

В случае аварии на АЭС имеет место как прямое выпадение радионуклидов на зеркало воды, так и смыв радионуклидов с речных водосборов. Прогнозные оценки коэффициентов смыва и параметров выноса радионуклидов за гидрологический период в случае аварии позволяют дать предполагаемую оценку загрязнения речной воды.

Таким образом, необходимо провести прогнозные оценки содержания радионуклидов в воде р. Вилия при аварии на БелАЭС, а также доз облучения населения с целью необходимости введения ограничений на потребление питьевой воды [2].

Цель исследования - расчет модулей смыва и коэффициентов смыва радионуклидов с водосборных территорий и оценка содержания радионуклидов в р. Вилия при запроектной аварии на Белорусской АЭС и доз облучения населения за счет потребления питьевой воды.

\section{Материалы и методы исследования}

Гидрографическая сеть в пределах 30-километровой зоны белорусской АЭС включает 70 водных объектов, из которых 5 являются трансграничными, 52 расположены на территории Беларуси, 13 - на территории Литвы.

К основным водным объектам района размещения площадки БелАЭС, относятся реки Вилия, Полпе, Гозовка, Страча, Ошмянка, Лоша.

Река Вилия - самый большой приток р. Неман. Вытекает она из небольшого болота, расположенного в 1 км северо-восточнее д. Великое поле Докшицкого р-на. Впадает в р. Неман с правого берега у г. Каунас. Длина реки составляет 498 км, в пределах Беларуси - 264 км. Схема водосборной площади р. Вилия, которая охватывает створ сброса технических сточных вод БелАЭС, приведена на рис. 1. 


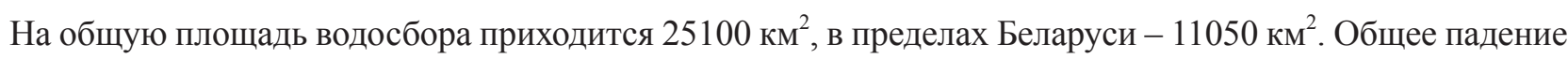
в пределах Беларуси составляет 90,6 м, средний уклон водной поверхности - 0,3 \%о, коэффициент извилистости $-1,98$.

Вода из р. Вилия может быть использована как для бытового и промышленного водоснабжения, так и нужд сельского хозяйства. В районе размещения БелАЭС вода для питьевого водоснабжения населения из р. Вилия не используется, однако при моделировании и оценке доз облучения населения принято предположение об использовании воды в питьевом водоснабжении.

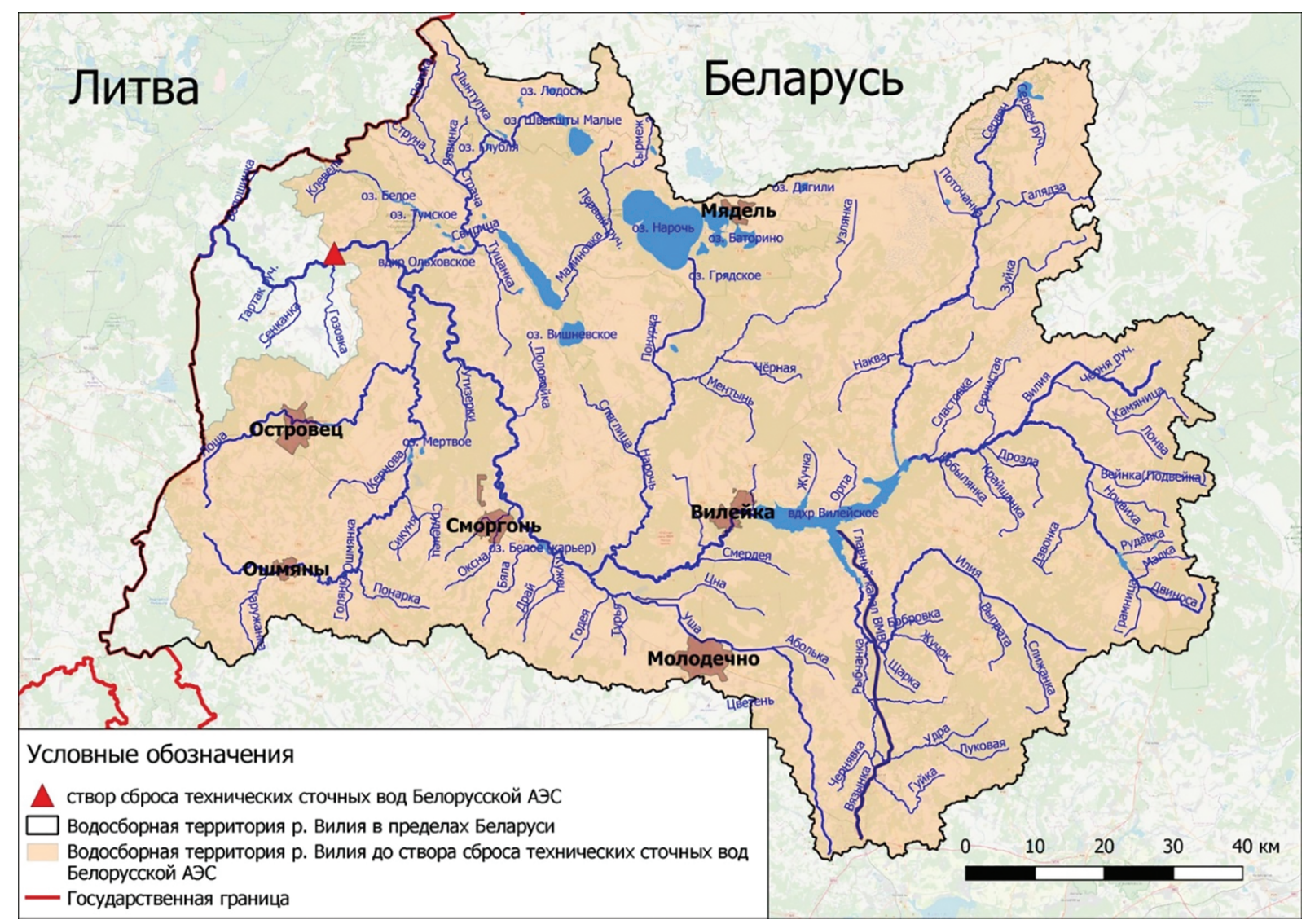

Рис. 1. Схема водосборной территории р. Вилия

Fig. 1. Scheme of the catchment area of the river Viliya

В качестве сценария запроектной аварии (далее - ЗА) на БелАЭС выбрана ситуация, рассмотренная в рамках подготовки Оценки воздействия на окружающую среду БелАЭС (далее - ОВОС). Состав выброса смоделированного за 1 сутки: ${ }^{131} \mathrm{I}-4,0 \cdot 10^{14} \mathrm{Б \kappa},{ }^{137} \mathrm{Cs}-3,5 \cdot 10^{14} \mathrm{Б \kappa},{ }^{90} \mathrm{Sr}-7,2 \cdot 10^{12}$ Бк, направление ветра выбрано по течению р. Вилия (в сторону Литвы). Результаты оценки плотности загрязнения территории радионуклидами ${ }^{131} \mathrm{I},{ }^{137} \mathrm{Cs}$ и ${ }^{90} \mathrm{Sr}$ приведены в табл.1 [3].

Поля плотности загрязнения территории ${ }^{137} \mathrm{Cs},{ }^{131} \mathrm{I}$ и ${ }^{90} \mathrm{Sr}$ на оси следа запад (3) приведены на рис. 2 [3].

Таблица 1

Плотность загрязнения территории радионуклидами при ЗА на оси следа 3, Бк/м² (24.03.2009)

Table 1

Density of contamination of the territory with radionuclides at beyond design basis accident on the track axis W, Bq / $\mathbf{m}^{2}(24.03 .2009)$

\begin{tabular}{|c|c|c|c|c|c|c|c|c|c|c|}
\hline \multirow{2}{*}{$\begin{array}{c}\text { Р/н } \\
\text { Бк/м }\end{array}$} & \multicolumn{10}{|c|}{ Расстояние, км } \\
\cline { 2 - 13 } & 0.5 & 1 & 2 & 3 & 5 & 10 & 15 & 20 & 25 & 30 \\
\hline${ }^{131} \mathrm{I}$ & $6,1 \mathrm{E}+03$ & $1,3 \mathrm{E}+04$ & $2,1 \mathrm{E}+05$ & $1,9 \mathrm{E}+05$ & $6,7 \mathrm{E}+05$ & $2,1 \mathrm{E}+06$ & $1,2 \mathrm{E}+06$ & $5,9 \mathrm{E}+05$ & $3,8 \mathrm{E}+05$ & $2,4 \mathrm{E}+05$ \\
\hline${ }^{137} \mathrm{Cs}$ & $3,5 \mathrm{E}+02$ & $4,8 \mathrm{E}+03$ & $7,2 \mathrm{E}+03$ & $8,5 \mathrm{E}+04$ & $3,9 \mathrm{E}+05$ & $2,9 \mathrm{E}+06$ & $1,6 \mathrm{E}+06$ & $7,3 \mathrm{E}+05$ & $3,8 \mathrm{E}+05$ & $2,3 \mathrm{E}+05$ \\
\hline${ }^{90} \mathrm{Sr}$ & $2,0 \mathrm{E}+03$ & $5,0 \mathrm{E}+03$ & $1,1 \mathrm{E}+04$ & $1,4 \mathrm{E}+04$ & $7,1 \mathrm{E}+03$ & $3,8 \mathrm{E}+03$ & $3,5 \mathrm{E}+03$ & $4,0 \mathrm{E}+03$ & $3,6 \mathrm{E}+03$ & $2,9 \mathrm{E}+03$ \\
\hline
\end{tabular}



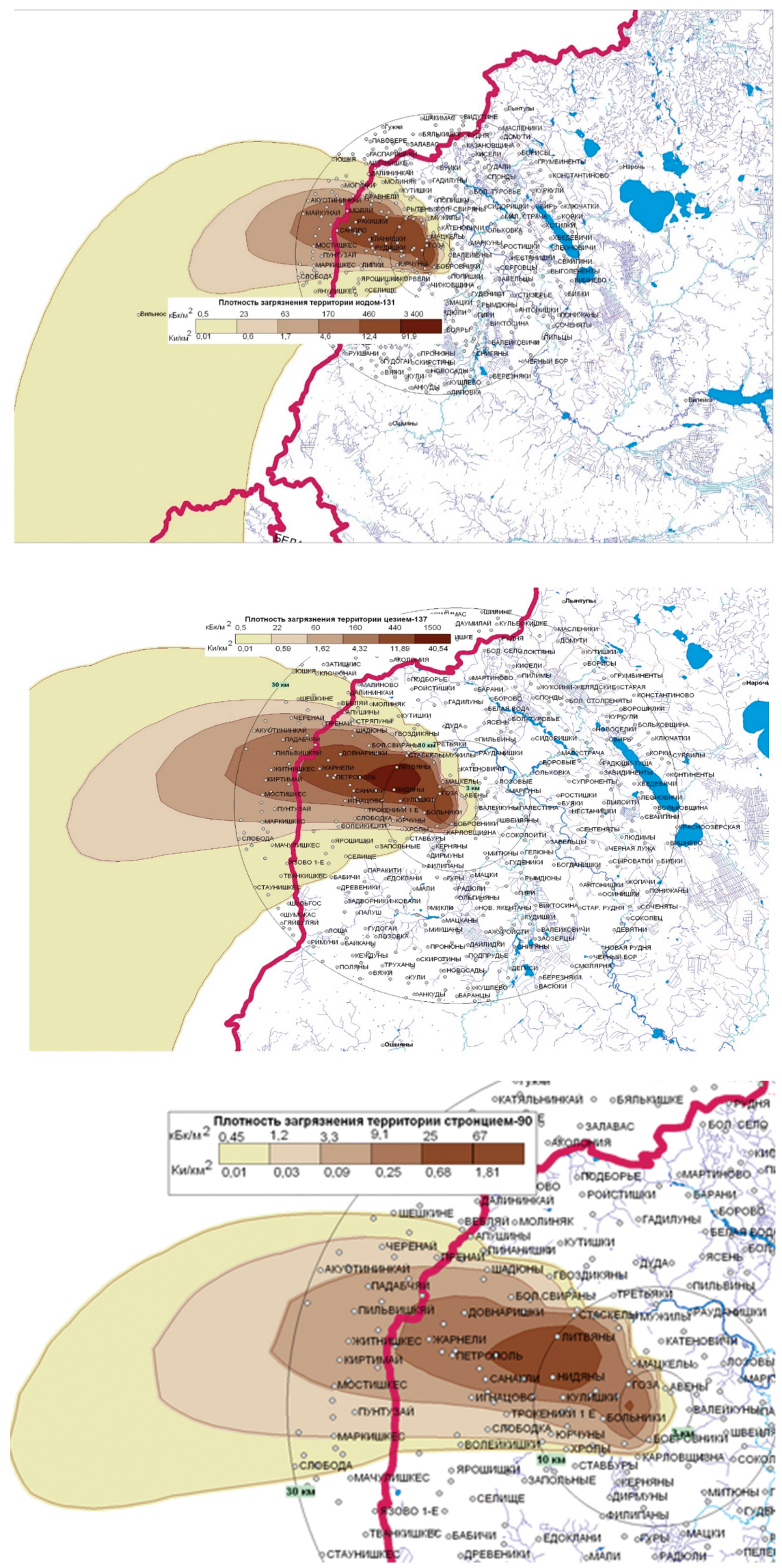

Puc. 2. Поля плотности загрязнения территории ${ }^{137} \mathrm{Cs},{ }^{131} \mathrm{I}$ и ${ }^{90} \mathrm{Sr}$ на оси следа запад (3)

Fig. 2. Density fields of contamination of the territory with ${ }^{137} \mathrm{Cs},{ }^{131} \mathrm{I}$ and ${ }^{90} \mathrm{Sr}$ on the axis of track west (W) 
При аварии необходимо оценивать смыв свежих продуктов выпадения на подстилающую поверхность. С этой целью проводится экспресс-оценка коэффициента (модуля) смыва радионуклидов с естественных водосборов с учетом ландшафтно-экологических условий конкретного водосбора.

Основным параметром смыва было принято считать величину отношения средней концентрации радионуклида в водном потоке $\overline{\mathrm{C}}$ (усреднение за наблюдаемый гидрологический период) к средней плотности загрязнения водосборного бассейна этим радионуклидом $\sigma$ (усреднение по водосборной площади выше створа наблюдения) [4]:

$$
M_{c}=\frac{\bar{C}}{\bar{\sigma}},
$$

где $C$ - средняя концентрации радионуклида в водном потоке, Бк/м³

$\sigma-$ средняя плотность загрязнения водосборного бассейна радионуклидом, Бк/м².

Величина $M_{c}$ м $^{-1}$ - «модуль смыва» загрязняющей атмосферной примеси, выпавшей на водосборный бассейн.

Другим полезным для прогнозных оценок параметром является полный коэффициент смыва $K_{c}$ за рассматриваемый гидрологический период (паводок, межень, год и т. д.). Это отношение полной активности какого-либо радионуклида в водном стоке через наблюдаемый створ к запасу этого радионуклида на всей водосборной площади:

$$
K_{c}(\Delta t)=\frac{\bar{C} W}{\bar{\sigma} S}
$$

где $W$ - полный объем водного стока через створ за время наблюдения, м³

$S$ - площадь водосборного бассейна реки выше створа наблюдения, м².

$\mathrm{K}_{\mathrm{c}}$ и $\mathrm{M}_{\mathrm{c}}$ связаны соотношением (3):

$$
K_{c}=M_{c} \frac{Q \Delta t}{S}=M_{c} M_{s} \Delta t,
$$

где $Q-$ средний расход воды, $\mathrm{m}^{3} / \mathrm{c}$, через створ за время $\Delta t$, с. Для целей настоящей оценки $\Delta t$ принят равным 1 месяц;

$M_{s}=Q / S-$ средний модуль водного стока, $\mathrm{m}^{3} /\left(\mathrm{c} \times \mathrm{M}^{2}\right)$.

Из общих соображений понятно, что данные прогностические параметры зависят от многих факторов, из которых определяющими являются $M_{6}$ и ландшафтно-экологические характеристики водосборной площади: масштаб водосбора, средний уклон, почвенно-растительные условия, степень антропогенной эрозионной нагрузки и т. п.

В то же время концентрация радионуклидов в речной воде будет формироваться физико-химическими процессами:

- смывом радионуклидов с поверхности ВСБ дождевыми осадками и в результате снеготаяния;

- поступлением растворимых форм радионуклидов с загрязненными подземными и почвенными водами;

- атмосферными выпадениями на водную поверхность водотока, которые обусловлены глобальными выпадениями, локальным ветровым подъемом и переносом пылевых частиц с поверхности водосборного бассейна.

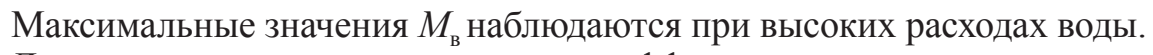

Для расчета параметров выноса и коэффициентов смыва радионуклидов с водосборных территорий было принято значение среднего многолетнего расхода воды в р. Вилия по данным многолетних наблюдений, который, составляет 52,9 м $3 / \mathrm{c}$.

Общая эффективная доза облучения от потребления питьевой воды оценивалась по формуле (4):

$$
E_{\text {water }}=\sum_{i=1}^{n} C_{i} \times U_{\text {water }} \times C F_{i} \times D I_{i} \times T_{\text {water }} \times 10^{6},
$$

где $E_{\text {water }}-$ общая эффективна доза облучения от потребления питьевой воды, мк3в;

$\mathrm{C}_{i}$ - концентрация радионуклида $i$ в питьевой воде, Бк/л;

$U_{\text {water }}$ - суточное потребление воды лицом определенной возрастной группы, л/день. В расчетах использованы данные о потреблении воды, характерные для европейского региона (табл. 2);

$\mathrm{C} F_{i}$ - ожидаемая эффективная доза облучения на единицу перорального поступления для населения, Зв/Бк [5];

$T_{\text {water }}$ - период потребления воды, дней;

$10^{6}$ - коэффициент перехода от Зв к мкЗв. 
Потребление воды и ожидаемая эффективная доза облучения на единицу перорального поступления для различных возрастных групп населения

Table 2

Water consumption and expected effective radiation dose per unit of oral intake for different age groups of the population

\begin{tabular}{|c|c|c|c|c|c|c|}
\hline Возрастная группа, лет & $0-1$ & $1-2$ & $2-7$ & $7-12$ & $12-17$ & $>17$ \\
\hline Потребление воды, л/год & 250 & 350 & 350 & 350 & 550 & 730 \\
\hline \multicolumn{2}{|c|}{ Ожидаемая эффективная доза облучения на единицу перорального поступления, Зв/Бк } \\
\hline${ }^{131} \mathrm{I}$ & $1,8 \mathrm{E}-07$ & $1,8 \mathrm{E}-07$ & $1,0 \mathrm{E}-07$ & $5,2 \mathrm{E}-08$ & $3,4 \mathrm{E}-08$ & $2,2 \mathrm{E}-08$ \\
\hline${ }^{137} \mathrm{Cs}$ & $2,1 \mathrm{E}-08$ & $1,2 \mathrm{E}-08$ & $9,6 \mathrm{E}-09$ & $1,0 \mathrm{E}-08$ & $1,3 \mathrm{E}-08$ & $1,3 \mathrm{E}-08$ \\
\hline${ }^{90} \mathrm{Sr}$ & $2,3 \mathrm{E}-07$ & $7,3 \mathrm{E}-08$ & $4,7 \mathrm{E}-08$ & $6,0 \mathrm{E}-08$ & $8,0 \mathrm{E}-08$ & $2,8 \mathrm{E}-08$ \\
\hline
\end{tabular}

\section{Результаты исследования и их обсуждение}

В табл. 3 представлены результаты расчетов прогнозных оценок радиоактивного загрязнения речной воды для водосбора (створа наблюдений) р. Вилия (д. Тартак). Эти параметры используются для экспрессных прогнозных оценок радиоактивного загрязнения речной воды в результате совокупности вторичных миграционных процессов - механического смыва, выщелачивания из почв, неравновесного обмена между фазами (взвесь - растворенные формы, вода - донные отложения).

Таблица 3

Результаты расчета прогнозных оценок «модуля смыва» и «коэффициента смыва» свежих продуктов выпадений для радионуклидов ${ }^{131} \mathrm{I},{ }^{137} \mathrm{Cs}$ и ${ }^{90} \mathrm{Sr}$ водосбора р. Вилия (д. Тартак)

Table 3

The results of calculating predictive estimates of the "washout module» and "washout coefficient» of fresh fallout products for radionuclides ${ }^{131} \mathrm{I},{ }^{137} \mathrm{Cs}$ and ${ }^{90} \mathrm{Sr}$ from the catchment of the river Viliya (village Tartak)

\begin{tabular}{|c|c|c|c|c|}
\hline Радионуклид & $\sigma$, Бк/м ${ }^{2}$ & С, Бк/л [2] & $\mathrm{M}_{c}, \mathrm{M}^{-1}$ & $\mathrm{~K}_{c}$, Бк/c \\
\hline${ }^{131} \mathrm{I}$ & $1,6 \mathrm{E}+06$ & 2,4 & $1,5 \mathrm{E}-03$ & $1,8 \mathrm{E}-02$ \\
\hline${ }^{137} \mathrm{Cs}$ & $2,4 \mathrm{E}+06$ & 2,2 & $0,92 \mathrm{E}-03$ & $1,1 \mathrm{E}-02$ \\
\hline${ }^{90} \mathrm{Sr}$ & $3,6 \mathrm{E}+03$ & 0,76 & 0,21 & 2,52 \\
\hline
\end{tabular}

Итоги прогнозных оценок, приведенные в табл. 3, согласуются с результатами натурных экспериментов, полученных для р. Ипуть (г. Добруш) на загрязненных после аварии на ЧАЭС территориях [5].

Значения средних концентраций радионуклидов в водном потоке р. Вилия в трансграничном створе при запроектной аварии на БелАЭС не превысят действующих уровней вмешательства в продуктах питания, молоке и воде (ДУВ7 - удельная активность радионуклидов в продуктах питания, молоке и питьевой воде составляет для ${ }^{331} \mathrm{I}-1000$ Бк/кг, для ${ }^{137} \mathrm{Cs}-200$ Бк/кг), что в 5-10 раз ниже референтных уровней содержания данных радионуклидов в питьевой воде - 10 Бк/л (табл. 3) [4].

Проведен расчет доз облучения различных возрастных групп населения за счет потребления питьевой воды из р. Вилия на участке вблизи д. Тартак за первые 7 дней после аварии с целью сравнения с национальными критериями аварийного реагирования, установленными в [4]. Результаты оценки приведены в табл. 4.

Таблица 4

Результаты оценки эффективной дозы облучения населения

за первые 7 дней от потребления питьевой воды из р. Вилия (д. Тартак), мкЗв

The results of assessing the effective dose of irradiation of the population

for the first 7 days from the consumption of drinking water from the river Viliya (village Tartak), $\mu \mathrm{Sv}$

\begin{tabular}{|c|c|c|c|c|c|c|}
\hline \multirow{2}{*}{ Радионуклид } & \multicolumn{7}{|c|}{ Возрастная группа } & 712 & $12-17$ & $>17$ \\
\cline { 2 - 7 } & $0-1$ & $1-2$ & $2-7$ & 0,60 & 0,39 & 0,25 \\
\hline${ }^{131} \mathrm{I}$ & 2,07 & 2,07 & 1,15 & 0,11 & 0,14 & 0,14 \\
\hline${ }^{137} \mathrm{Cs}$ & 0,22 & 0,13 & 0,10 & 0,11 & 0,10 \\
\hline${ }^{90} \mathrm{Sr}$ & 0,84 & 0,27 & 0,17 & 0,22 & 0,29 & 0,49 \\
\hline От суммы радионуклидов & 3,13 & 2,46 & 1,42 & 0,92 & 0,82 & 0,49 \\
\hline
\end{tabular}


Уровни доз облучения населения при запроектной аварии на БелАЭС (табл. 4) не превысят общих критериев реагирования для проведения ограничения потребления питьевой воды - эффективная доза 100 м3в за первые 7 дней [4].

\section{Заключение}

При запроектных аварийных ситуациях на БелАЭС модуль смыва свежих продуктов выпадений для водосбора р. Вилия (д. Тартак) составит $1,5 \times 10^{-3} \mathrm{~m}^{-1}, 0,92 \times 10^{-3} \mathrm{~m}^{-11} 0,21 \mathrm{~m}^{-1}$ для радионуклидов ${ }^{131} \mathrm{I},{ }^{137} \mathrm{Cs}$ и ${ }^{90} \mathrm{Sr}$ соответственно. Коэффициенты смыва для данных радионуклидов будут равны $1,8 \times 10^{-2}$ Бк/c, $1,1 \times 10^{-2}$ Бк/с и 2,52 Бк/с для ${ }^{131} \mathrm{I},{ }^{137} \mathrm{Cs}$ и ${ }^{90} \mathrm{Sr}$ соответственно.

Значения концентраций радионуклидов ${ }^{131} \mathrm{I}$ и ${ }^{137} \mathrm{Cs}$ в водном потоке р. Вилия в трансграничном створе при запроектной аварии на БелАЭС не превысят действующих уровней вмешательства в продуктах питания, молоке и воде (ДУВ7).

Результаты оценки годовых эффективных доз облучения от потребления воды из р. Вилия различных возрастных групп населения, проживающего на границе с Литвой, указывают на отсутствие необходимости проведения срочных защитных мероприятий в виде ограничения потребления питьевой воды из открытых источников (критерий реагирования 100 мЗв за первые 7 дней превышен не будет). Однако при более длительном использовании воды из р. Вилия для питьевого и хозяйственного назначения данной дозы облучения населения она может быть значительно выше за счет увеличения коэффициентов смыва и выноса радионуклидов с загрязненных водосборных территорий.

Таким образом, имеющаяся сеть пунктов наблюдения за поверхностными водами должна быть расширена для оперативной оценки содержания радионуклидов в поверхностных водах, выноса радионуклидов через гидростворы и определения модуля смыва свежих продуктов деления при радиационной аварии. Колодцы должны быть защищены от попадания радионуклидов, выпадающих из атмосферы. Кроме того, при аварии необходим контроль содержания радионуклидов в воде из колодцев, особенно в тех населенных пунктах, где они являются преобладающим источником питьевого водоснабжения населения.

\section{Библиографические ссылки}

1. Konoplev A, Kanivets V, Laptev G, Voitsekhovich O, Zhukova O, Germenchuk M. Long-term dynamics of the Chernobyl-derived radionuclides in rivers and lakes In: Konoplev A, Kato K, Kalmykov S, editors. Behavior of Radionuclides in Environment II: Chernobyl. Tokyo: Springer; 2020. p. 323-348.

2. Кляус ВВ. Дозы внутреннего облучения населения при максимальной проектной и запроектной авариях на АЭС. 3доровье и окружающая среда. 2009;13:91-97.

3. ОВОС. Книга 11, часть 3.4. Проектные и запроектные аварии. Радиоактивные выбросы. Трансграничное влияние, 2009.

4. Ветров ВА, Козарезов ЕВ, Алексеенко ВА. и др. Смыв радионуклидов с естественных водосборов бассейна Днепра. Метеорология и гидрология. 1990;2:120-123.

5. Критерии оценки радиационного воздействия: гигиенический норматив: утверждено постановлением Министерства здравоохранения Республики Беларусь 28.12.2012 г. № 213. Радиационная гигиена. 2015;4:34-167.

6. Жукова ОМ, Матвеенко ИИ, Мышкина НК, Шароваров ГА, Ширяева НМ. Формирование и динамика распространения радиоактивного загрязнения в реках Беларуси после аварии на Чернобыльской АЭС. Инженерно-физический журнал. 1997;70(1):73-81.

\section{References}

1. Konoplev A, Kanivets V, Laptev G, Voitsekhovich O, Zhukova O, Germenchuk M. Long-term dynamics of the Chernobyl-derived radionuclides in rivers and lakes In: Konoplev A, Kato K, Kalmykov S, editors. Behavior of Radionuclides in Environment II: Chernobyl. Tokyo: Springer; 2020. p. 323-348.

2. Kliaus VV. Doses of internal exposure of the population at the maximum design and beyond design basis accidents at NPP. Zdorovie i okruzhajushchaya sreda [Health and Environment].2009;13:91-97. Russian.

3. OVOS. Kniha 11, chast 3,4. Proektnye i zaproektnye avarii. Radioaktivnye vybrosy. Transgranichnoe vlijanie [EIA. Book 11, part 3.4. Design and beyond design basis accidents. Radioactive emissions. Transboundary Impact]. 2009. Russian.

4. Vetrov VA, Kozarezov EV, Alekseenko VA, et al. Flushing of radionuclides from natural catchments of the Dnieper basin. Meteorologia $i$ hidrologia [Meteorology and hydrology].1990;2:120-123. Russian.

5. Criteria for assessing radiation exposure: hygienic standard: approved Resolution of the Ministry Health Resp. Belarus 2012 December 28 No. 213. Radiatsionnaya hihiena [Radiation hygiene]. 2015;4:34-167. Russian.

6. Zhukova OM, Matveenko II, Myshkina NK, Sharovarov GA, Shiryaeva NM. Formation and dynamics of the spread of radioactive pollution in the rivers of Belarus after the accident at the Chernobyl nuclear power plant. Inzhenerno-fizicheskiy zhurnal [Engineering Physics Journal]. 1997;70(1):73-81. Russian. 